\title{
Video transects as a complement to underwater visual census to study reserve effect on fish assemblages
}

\author{
Anne Tessier ${ }^{1,2, *}$, Jérémy Pastor $^{1,2,3}$, Patrice Francour ${ }^{3}$, Gilles Saragoni ${ }^{1,2}$, \\ Romain Crec'hriou $^{1,2}$, Philippe Lenfant ${ }^{1,2}$
}

${ }^{1}$ Université de Perpignan Via Domitia, Centre de Formation et de Recherche sur les Environnements Méditerranéens, UMR 5110,52 avenue Paul Alduy, 66860 Perpignan, France

${ }^{2}$ CNRS, Centre de Formation et de Recherche sur les Environnements Méditerranéens, UMR 5110, 52 avenue Paul Alduy, 66860 Perpignan, France

${ }^{3}$ University de Nice-Sophia Antipolis, EA 4228 ECOMERS, Parc Valrose, 06108 Nice, France

\begin{abstract}
The present study focuses on the use of diver-operated video (DOV) as a tool to evaluate the impact of a marine reserve on a fish assemblage, in comparison to underwater visual census (UVC). Samplings were conducted in the vicinity of the marine protected area (MPA) CerbèreBanyuls (northwestern Mediterranean Sea). Four sites, with different levels of protection, were sampled 4 times, at depths of 5 and $10 \mathrm{~m}$, to study abundance, species richness, structure of fish assemblages and fish aggregation. Results obtained by DOV and UVC provided evidence of significant effects of protection on abundance, species richness and fish assemblages. However, detection of weaker reserve effects using DOV may be limited. Furthermore, certain species are difficult to identify by video (e.g. Symphodus spp.), but DOV may be useful when studying a target and/or easily identifiable species. Contrary to UVC, DOV data can be archived and used for further study. Results concerning fish aggregation within fish assemblages showed specific patterns. Sites outside the MPA were mainly characterized by the absence of fish or few fish aggregations, and sites inside were characterized by high fish density (i.e. dispersed or patched aggregations). Thus, the fish aggregation parameter measured using DOV is an interesting metric to quantify reserve effect. Consequently, although this technique is time-consuming to produce results, DOV presents great potential for estimating MPA effectiveness while allowing simultaneous work on several sites to limit temporal bias.
\end{abstract}

KEY WORDS: MPA · Marine protected area · Reserve effect · Underwater video · Visual census · Mediterranean Sea $\cdot$ Fish

Resale or republication not permitted without written consent of the publisher

\section{INTRODUCTION}

Marine protected areas (MPAs) are an effective management tool to preserve marine biodiversity or resources and to prevent environmental degradation (e.g. Gell \& Roberts 2003, Guidetti \& Sala 2007, Himes 2007, Fenberg et al. 2012). The evaluation of their performance can be reviewed through (1) monitoring of the density and biomass of the targeted species (e.g. Côté et al. 2001, Ferraris et al. 2005, Claudet et al. 2011) or (2) biodiversity indicators, such as environmental health and the functioning of ecosystems (Bianchi \& Morri 2000, Hilty \& Merenlende 2000).

MPA creation may lead to a reserve effect induced by the effect of protection. A reserve effect reveals itself through an increase in (1) global species richness, (2) density, particularly that of species targeted by fishing (professional and recreational), and (3) frequency of large individuals compared to outside of the reserve (e.g. Alcala \& Russ 1990, Francour 1994, 
Harmelin et al. 1995, Vacchi et al. 1998, Mosquera et al. 2000, García-Charton et al. 2004, Hussein et al. 2011, Sahyoun et al. 2013).

Other phenomena, such as spillover or propagule effects, may be observed in the adjacent areas. This may be due to an exportation of eggs, larvae, juveniles or adult individuals (Sabatés et al. 2003, Di Franco et al. 2012) and may contribute to the recolonization and increased catches of target species (Sabatés et al. 2003, Guidetti 2007, Harmelin-Vivien et al. 2008).

The study of reserve effect and performance effectiveness of MPAs requires data on fish assemblages. Such data can be sampled through destructive methods: angling, trawling, fixed nets or spearfishing (Willis et al. 2000, Cappo et al. 2004). In contrast, non-destructive methods, like underwater visual census (UVC: strip transect, point count or fish assemblage survey techniques), are also available (e.g. Harmelin-Vivien et al. 1985, Seytre \& Francour 2009). UVC is generally preferred in MPAs and for the study of particular species (e.g. species with IUCN protection status).

Despite the worldwide use of UVC, numerous biases exist and are well documented. Biases are linked to the observer but also to factors that are intrinsic to the species observed (e.g. HarmelinVivien et al. 1985, Harvey et al. 2004, Cole et al. 2007). Furthermore, several parameters can limit the amount of scientific data collected on fish assemblages, such as dive time, depth, climatic conditions and sea temperature (Francour et al. 1999, Colton \& Swearer 2010).

To reduce biases and limiting parameters, scientists have increasingly resorted to using video survey systems, such as baited (or unbaited) remote underwater video (BRUV) during the day or night (Francour et al. 1999, Denny et al. 2004, Harvey et al. 2007, 2012, Colton \& Swearer 2010). These video methods are used to avoid some biases due to UVC (e.g. presence of the diver) but also to overcome limiting dive constraints (dive time, depth and sampling at dusk and dawn, facilitated by the high light-sensitivity of video; Francour et al. 1999). The use of video has the further advantage of enabling simultaneous studies to be carried out in different sites because it does not require a person able to identify the species in the field since identification is done in the laboratory. Thus, studies comparing UVC to video are becoming more frequent. They compare mainly UVC to BRUV (Willis \& Babcock 2000, Willis et al. 2000, Stobart et al. 2007, Colton \& Swearer 2010), omitting other methods of sampling using video.
The present study focuses on diver-operated video (DOV). Underwater video transects have been used sporadically for studies of fish (Boland \& Lewbel. 1986, Michalopoulos et al. 1992, Tessier et al. 2005, Pelletier et al. 2011), in contrast to benthos (e.g. algae or corals). DOV, like other video methods, is less costefficient than UVC. In fact, the data acquisition time is greater for video because those data are acquired through analysis of videotapes in the laboratory (Francour et al. 1999), while in UVC, data are acquired directly in the field during the dive. Thus, with video, there is the time in the field and the time in the laboratory to visualize the video clip. Furthermore, DOV is less cost-efficient than other video methods. Like UVC, it requires divers and a similar amount of diving time, but it entails the additional cost needed for post-treatment in the laboratory. However, it may allow access to the aggregation of fish along a transect, which is not possible in UVC or methods using a fixed camera. A strong relationship between fishes and habitat has now been proven (e.g. Letourneur et al. 2003, García-Charton et al. 2004). As species richness is high in MPAs, it seems that information about spatial fish distribution and the presence of fish aggregation (with several species) could provide a new indicator for evaluating the effectiveness of MPAs.

However, it is obvious that like other methods (e.g. UVC and BRUV), this method will present biases (Colton \& Swearer 2010), but DOV could be complementary to UVC to study fish assemblages and to detect a marine reserve effect. With the reserve effect, the number of fish often increases inside the reserve; thus, there is a greater possibility of inter- or intraspecies aggregation of fish. As individual abundance increases in a given space, the aggregation of individuals also increases. This can be due to a lack of space, to grouping behaviour to escape predators or to finding food or shelter (Landeau \& Terborgh 1986, Ward \& Hart 2005). In fact, with the reserve effect, the food chain is more complex; thus, interactions between species are more varied, and a species has potentially more predators (Pauly et al. 1998, Guidetti \& Sala 2007).

The purpose of the present paper is twofold. The first aim was to determine if DOV, like UVC, can indicate marine reserve effect. Fish assemblage abundance and the species richness stemming from both methods were compared regarding the reserve effect. The present study was carried out at the Cerbère-Banyuls marine reserve (France, Mediterranean Sea), which is known to have an effective reserve effect (Bell 1983, Dufour et al. 1995, Harmelin- 
Vivien et al. 2008, Claudet et al. 2011). To compare UVC to DOV, a cost-benefit analysis was carried out for each method. The second objective of the present paper was to determine if a metric related to fish aggregation and assessed by DOV could provides additional information about marine reserve effect on ichthyofauna.

\section{MATERIALS AND METHODS}

\section{Study area}

The study site is located in the south of France in the Mediterranean Sea (Fig. 1) in the vicinity of the Cerbère-Banyuls MPA. It is oriented north-south,

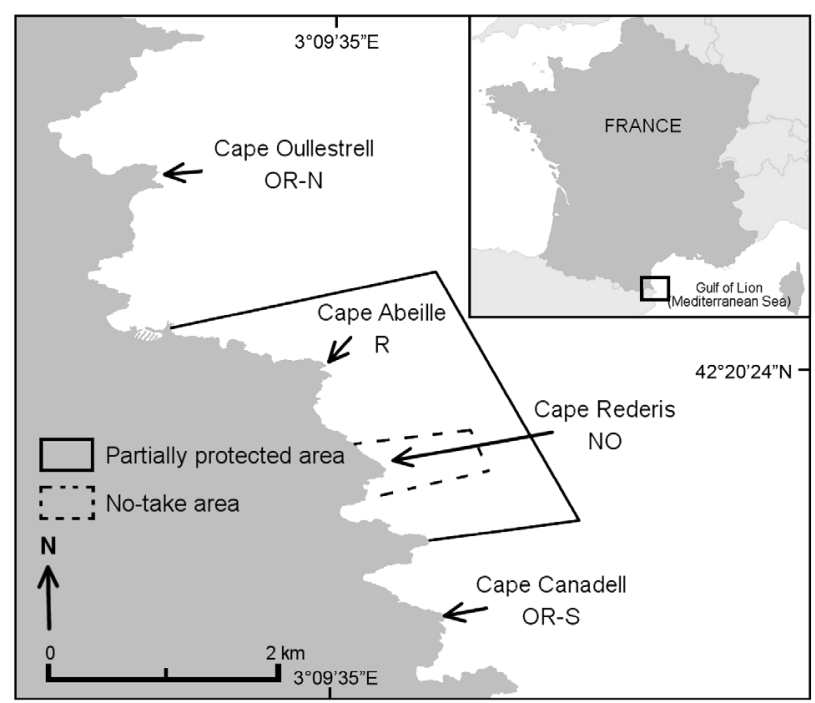

Fig. 1. Sampling locations along the French Catalan coast in SW France. OR-N/S: outside reserve north/south; R: reserve; NO: no-take area and includes bays and capes. Underwater slopes can be steep, and fish habitats are diverse, including Posidonia meadows, coralligenous rocks, rocks and sand. Four sites with similar habitats but with different levels of protection and fishing pressure were selected: Cape Rédéris in the no-take area (NO); Cape Abeille in the partially protected, regulated part of the reserve (R); Cape Canadell, south of the reserve, unprotected with moderate fishing pressure (OR-S); Cape Oullestrell, north of the reserve, with high fishing pressure (OR-N) (Table 1), All sites had similar exposure to wind and waves, including an uneven rocky area colonised by Posidonia meadows, algae and white gorgonians Eunicella singularis (Esper, 1794).

\section{Sampling methods}

To limit any efects caused by changes in environmental conditions, sampling was conducted over $4 \mathrm{~d}$ during the summer of 2008 (between 21 and 28 August). Two visual census techniques (UVC and DOV) were used at each site at $5 \mathrm{~m}$ and $10 \mathrm{~m}$ depths. The sampling protocol consisted of 4 replicates (chosen randomly) per site, per depth and per method, yielding 63 samples (1 DOV sample was not available due to technical error).

The UVC method consisted of a transect belt of $5 \times$ $50 \mathrm{~m}\left(250 \mathrm{~m}^{2}\right)$. The distance of $50 \mathrm{~m}$ was measured using a pentameter (Harmelin-Vivien et al. 1985). An experienced scientific diver swam at constant speed along the transect and noted the species observed on a slate. The same diver conducted all UVC counts to avoid biases due to the observer.

DOV surveys were carried out with a colour video camera placed in an underwater housing. All DOVs were made by the same video operator swimming

Table 1. Characteristics of sampling sites. OR-N: outside reserve north; OR-S: outside reserve south; R: reserve; NO: no-take area

\begin{tabular}{|c|c|c|c|c|c|c|}
\hline \multirow[t]{2}{*}{ Code } & \multirow[t]{2}{*}{ Sites } & \multirow[t]{2}{*}{ Location } & \multicolumn{2}{|c|}{ Distance to } & \multirow[t]{2}{*}{ Protection status } & \multirow{2}{*}{$\begin{array}{l}\text { Fishing } \\
\text { pressure }\end{array}$} \\
\hline & & & $\begin{array}{l}\text { No-take } \\
\text { area }\end{array}$ & $\begin{array}{c}\text { Partially } \\
\text { protected area }\end{array}$ & & \\
\hline OR-N & Cape Oullestrell & $42^{\circ} 30^{\prime} \mathrm{N}, 3^{\circ} 08^{\prime} \mathrm{E}$ & $4 \mathrm{~km}$ & $3 \mathrm{~km}$ & $\begin{array}{l}\text { Unprotected area: artisanal and } \\
\text { recreational fishing are not regulated }\end{array}$ & High \\
\hline $\mathrm{R}$ & Cape Abeille & $42^{\circ} 29^{\prime} \mathrm{N}, 3^{\circ} 09^{\prime} \mathrm{E}$ & $1 \mathrm{~km}$ & - & $\begin{array}{l}\text { Partially protected area: artisanal and } \\
\text { recreational fishing are regulated }\end{array}$ & Controlled \\
\hline NO & Cape Rédéris & $42^{\circ} 28^{\prime} \mathrm{N}, 3^{\circ} 10^{\prime} \mathrm{E}$ & - & $1 \mathrm{~km}$ & $\begin{array}{l}\text { No-take area: all human activities } \\
\text { are prohibited }\end{array}$ & No pressure \\
\hline OR-S & Cape Canadell & $42^{\circ} 27^{\prime} \mathrm{N}, 3^{\circ} 10^{\prime} \mathrm{E}$ & $2 \mathrm{~km}$ & $3 \mathrm{~km}$ & $\begin{array}{l}\text { Unprotected area: artisanal and } \\
\text { recreational fishing are not regulated }\end{array}$ & Moderate \\
\hline
\end{tabular}


alongside the diver who performed the UVC and were made at the same speed. The camera operator swam $1.5 \mathrm{~m}$ above the bottom and, keeping the video camera steady and perpendicular to the bottom, recorded in front of himself. The area sampled in DOV is lower than in UVC (the camera's field of view angle is smaller than the human eye), and this area has not been estimated. However, the sampling area of the DOV transects is standard because the camera was always $1.5 \mathrm{~m}$ from the bottom and kept in the same position. Furthermore, the conditions of visibility were identical $(10 \mathrm{~m})$ during the sampling period (between 21 and 28 August). In the laboratory, the videos were analysed on a computer. A single viewer watched all of the video recordings to avoid a multiple-observer bias. The individuals observed were identified to species level or, in some cases, to genus level. To improve the viewer's ability to identify fish (Colton \& Swearer 2010), each video was examined twice: a first reading to become familiar with the species and a second one to determine them. The number of individuals observed was also estimated, using freeze-frame when the number of specimens in movement was too high.

To determine whether fish aggregation was suitable as a reserve effect metric, the present study was carried out only on videos recorded at a depth of $10 \mathrm{~m}$. Fifteen freeze-frames were taken randomly on each video transect, and a code of fish aggregation was attributed to each. After a preliminary study, 15 freeze-frames appeared to be the minimum number necessary to be representative of fish aggregation for a video of $\sim 7 \mathrm{~min}$. The fish aggregation code was applied without considering the species, only individuals. Five codes of fish aggregation were defined (Fig. 2): 'No fish' when no individual was observed in the freeze-frame, 'Isolated' if 1 to 3 fish were visible, 'Scattered' when fish were not observed in clusters, 'Fragmented' when fish were grouped in a cluster but with a certain distance between them (more than twice the individual length of fish) and 'Patch' if fish were in schools with a short distance between individuals (less than twice the individual length of fish).

\section{Data analysis}

Chromis chromis (Linnaeus, 1758) and Coris julis (Linnaeus, 1758) were not considered for the analysis of abundance and structure of fish assemblages because their high abundance at all of the studied sites increased the variance and limited statistical comparison (Francour 1997). C. chromis and C. julis also have gregarious behaviour that can mask the protection effect (García-Charton et al. 2004, Forcada et al. 2008).

Analyses were performed using the $\mathrm{R} 2.9 .0$ software (R Development Core Team 2008) and the Primer v6 multivariate statistics package (Clarke \& Gorley 2006).

Univariate analyses were carried out to compare fish abundance and species richness among sites with both methods. Appropriate tests were used after validation of the conditions of application. The effect of protection status and depth on abundance and species richness was tested using a Scheirer-Ray-Hare's test (a non-parametric 2-way ANOVA; Sokal \& Rohlf 1995). An a posteriori test (Mann-Whitney) was performed when the 2-way ANOVA detected a significant difference. This test was used to identify the modalities of the factor associated with the variation in the response variable. In order to compromise between a large overall Type I error and a large overall Type II error (with the application of a Bonferroni correction), a p-value of 0.01 was used in each separate $a$ posteriori test.

To study the structure of fish assemblage analysis according to the method, sites and depths, we examined non-metric multi-dimensional scaling plots (nMDS) based on Bray-Curtis similarity coefficients. Hierarchical clusters based on group-average linkages of Bray-Curtis similarity coefficients were combined on the nMDS plots (Forcada et al. 2008). A permutational multivariate ANOVA (PERMANOVA; 9999 permutations) on Bray-Curtis similarity coefficients was made to identify significant differences in the proportion of each species in relation to a given factor using NPMANOVA software (Anderson 2000). An a posteriori test (Student's $t$-test with 9999 permutations) was used when a PERMANOVA indicated a significant difference.

The time required to collect and analyse data was used to conduct a cost-benefit analysis. Time cost was calculated on both a 'working hour' and a 'total day' basis for the involvement of 1 diver who performed daily $1 \mathrm{~h}$ dives and 1 person working $6 \mathrm{~h} \mathrm{~d}^{-1}$ in the laboratory (Francour et al. 1999).

To assess the suitability of DOV (through the 'fish aggregation' variable) for studying reserve effect, we performed chi-squared tests to analyse inter- and intra-site distribution concerning fish aggregation. 

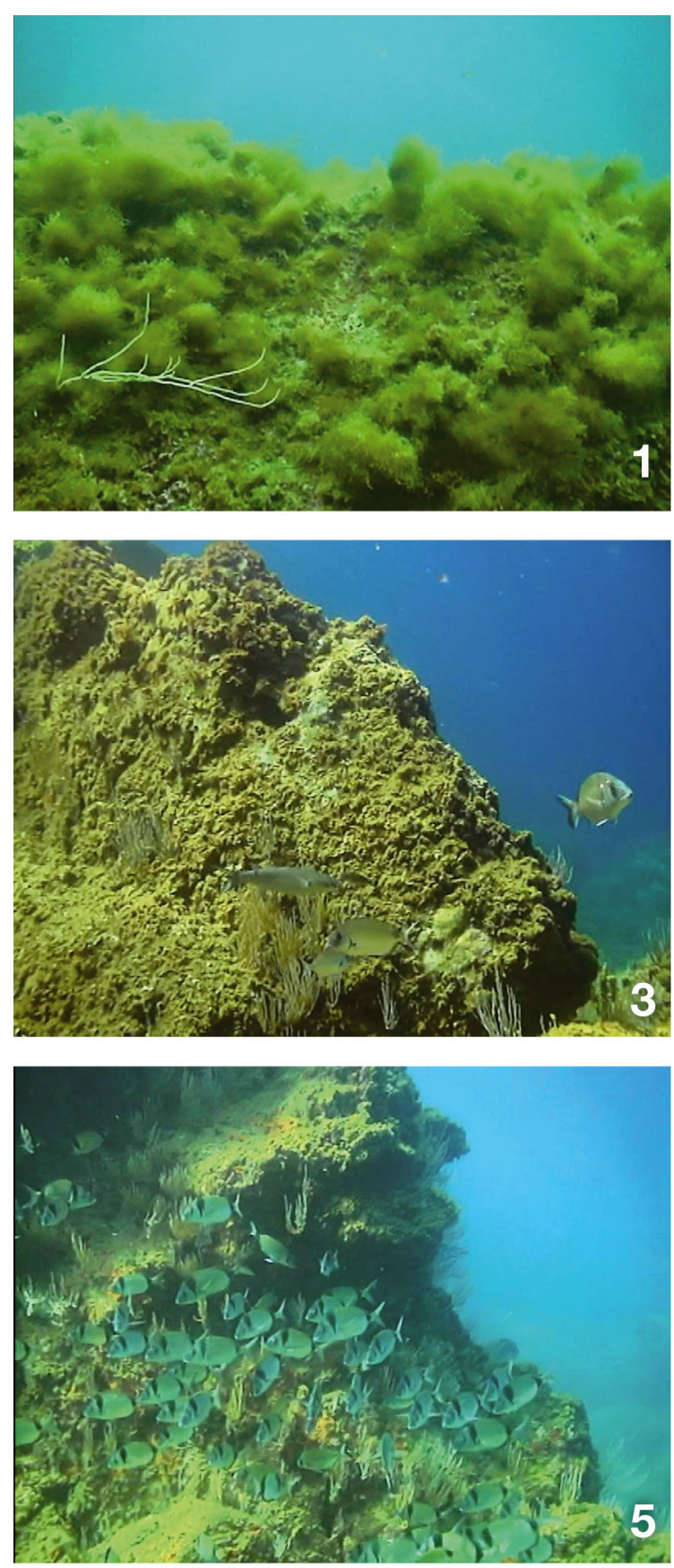

\section{RESULTS}

A total of 24 species belonging to 8 families were recorded using DOVs at all of the sites combined, and 30 species belonging to 9 families were recorded using UVC. Six species were observed only by UVC. All species observed by DOV were viewed by UVC. A total of 11439 fish were counted: 8890 in UVC and 2549 in DOV, i.e. 3.5 -fold more individuals were counted by UVC.
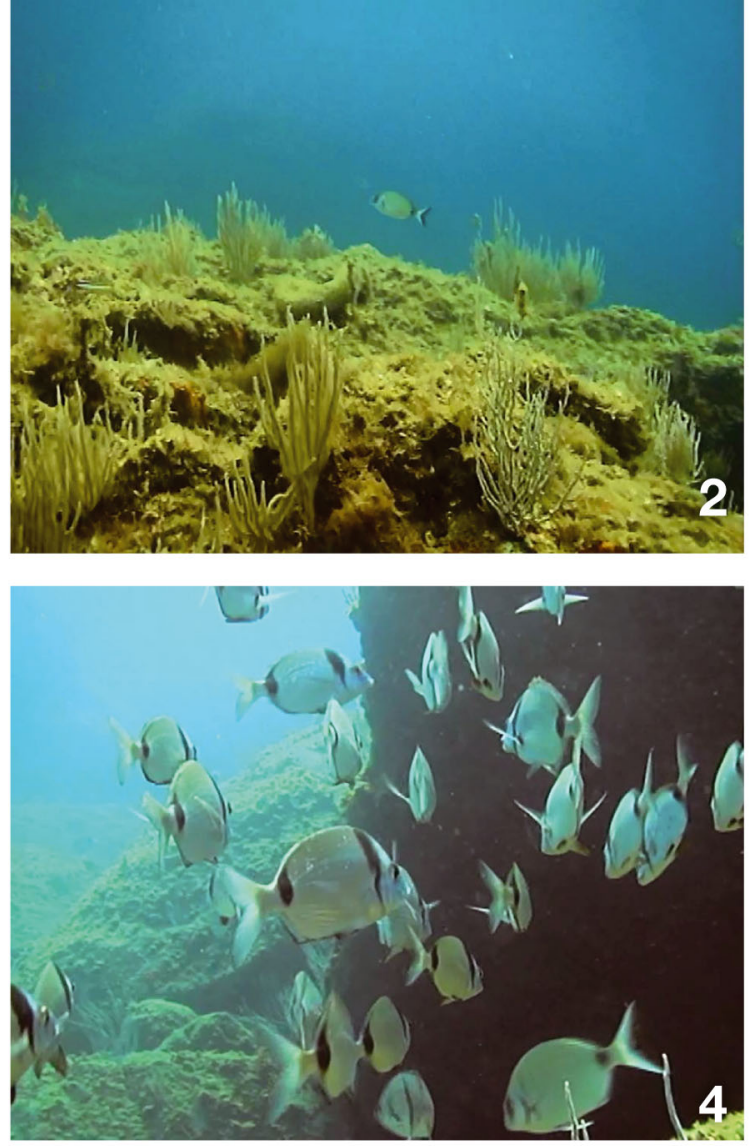

Fig. 2. Example video frames illustrating codes of fish aggregation. 1: No fish; 2: Isolated; 3: Scattered; 4: Fragmented; 5: Patch

\section{Fish abundance and species richness}

The maximum abundance was encountered at NO for both methods (UVC: 1316 per $250 \mathrm{~m}^{2}$; DOV: 297 per transect with an unknown, smaller area), i.e. $\sim 4.5$-fold more individuals were observed by UVC. The minimum abundance was found at OR-N by UVC and DOV (UVC: 22 per $250 \mathrm{~m}^{2}$; DOV: 1 per transect; 22 -fold more individuals observed by UVC). For both methods, mean abundance differed significantly among sites (UVC: $p<0.001$; DOV: $p<0.001$; Table 2) and mean abundance was significantly smaller at OR-N than at NO (UVC: 74.12 vs. 566.25 , $\mathrm{p}<0.001$; DOV: 15.37 vs. 178.25, p < 0.0005; Fig. 3). For UVC, a significantly lower mean abundance was detected at OR-N than at OR-S (Mann-Whitney test, UVC: 74.12 vs. 298.87, p < 0.005; Fig. 4).

Both methods identified maximum species richness at NO (UVC: 15 per $250 \mathrm{~m}^{2}$, DOV: 12 per transect), 
Table 2. Comparison of 2 methods used to measure abundance and species richness in 4 sampling areas. UVC: underwater visual census; DOV: diver-operated video; OR-N: outside reserve north; OR-S: outside reserve south; R: reserve; NO: no-take area; n: number of replicates

\begin{tabular}{|c|c|c|c|c|c|c|c|c|c|c|c|c|c|c|c|}
\hline \multirow[t]{2}{*}{ Variable } & \multirow[t]{2}{*}{ Method } & \multicolumn{3}{|c|}{$\longrightarrow$ OR-N- } & \multicolumn{3}{|c|}{$\mathrm{R}$} & \multicolumn{3}{|c|}{$-\mathrm{NO}=$} & \multicolumn{3}{|c|}{$\longrightarrow$ OR-S } & \multirow[t]{2}{*}{$F$} & \multirow[t]{2}{*}{$\mathrm{p}$} \\
\hline & & Mean & SE & $\mathrm{n}$ & Mean & $\mathrm{SE}$ & $\mathrm{n}$ & Mean & SE & $\mathrm{n}$ & Mean & $\mathrm{SE}$ & $\mathrm{n}$ & & \\
\hline \multirow[t]{2}{*}{ Abund. } & UVC & 74.12 & 73.78 & 4 & 172.00 & 157.09 & 4 & 566.25 & 416.35 & 4 & 298.87 & 163.10 & 4 & 9.825 & 0.0002 \\
\hline & DOV & 15.37 & 12.05 & 4 & 77.12 & 69.44 & 4 & 178.25 & 89.45 & 4 & 54.71 & 42.56 & 3 & 10.329 & 0.000016 \\
\hline \multirow{2}{*}{$\begin{array}{l}\text { Species } \\
\text { richness }\end{array}$} & UVC & 11.25 & 2.12 & 4 & 12.62 & 1.77 & 4 & 13.37 & 1.60 & 4 & 9.12 & 1.81 & 4 & 8.306 & 0.0005 \\
\hline & DOV & 5.50 & 1.95 & 4 & 8.50 & 1.95 & 4 & 8.37 & 1.92 & 4 & 7.00 & 1.73 & 3 & 5.769 & 0.004 \\
\hline
\end{tabular}

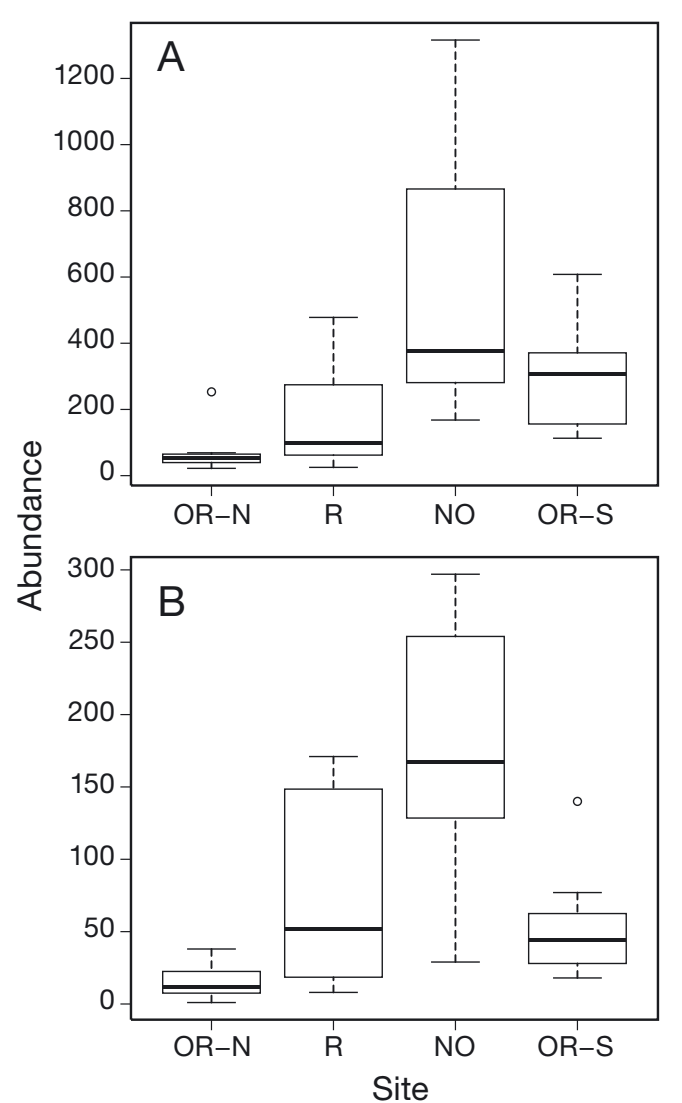

Fig. 3. Boxplot of mean abundances of fish at 4 sites in and near the marine protected area, comparing 2 methods. (A) UVC. Mean abundance at OR-N is significantly different from that at NO $(p<0.01)$ and OR-S (p < 0.05). (B) DOV. Mean abundance at OR-N is significantly different from that at NO $(p<0.0005)$. See Table 2 for abbreviations

however minimum species richness was identified at different sites (UVC: 7 species at OR-S ; DOV 3 species at OR-N). Mean species richness differed significantly among sites independent of method (UVC: $\mathrm{p}<0.001$; DOV: $\mathrm{p}<0.005$; Table 2) and was significantly lower at the OR sites than at NO and R. However, the OR site with the lowest measured richness depended on the method. OR-S presented lower spe-

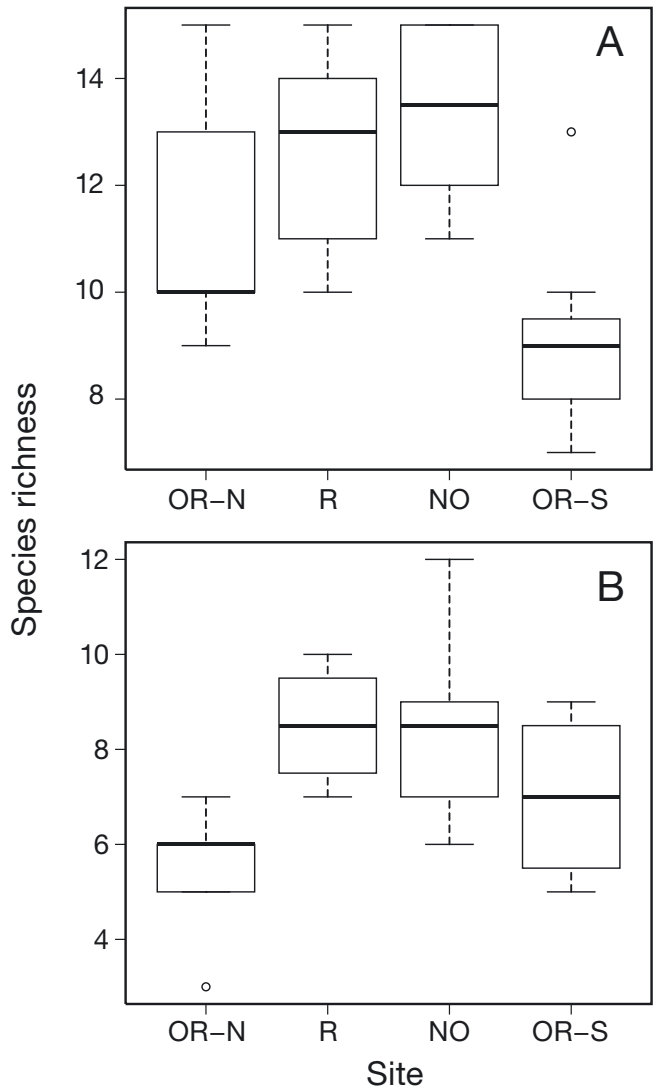

Fig. 4. Boxplot of mean species richness at 4 sites in and near the marine protected area, comparing 2 methods. (A) UVC. Mean species richness at OR-N is significantly different from that at OR-S ( $p<0.005)$ and NO ( $<$ 0.0005). (B) DOV. Mean species richness at OR-N is significantly different from that at $\mathrm{R}$ $(p<0.005)$ and NO $(p<0.0005)$. See Table 2 for abbreviations

cies richness for UVC (Mann-Whitney test, OR-S vs. NO: 9.12 vs. $13.37, \mathrm{p}<0.005$; OR-S vs. R: 9.12 vs. 12.62, $\mathrm{p}<0.005$; Fig. 4). In contrast, the lowest species richness was at OR-N for DOV (OR-N vs. NO: 5.62 vs. $8.37, \mathrm{p}<0.005$ and $\mathrm{OR}-\mathrm{N}$ vs. R: 5.62 vs. 8.62 , $\mathrm{p}<0.005$; Fig. 4).

All of the species observed by DOV were also observed by UVC (Table 3), whereas 6 species were 


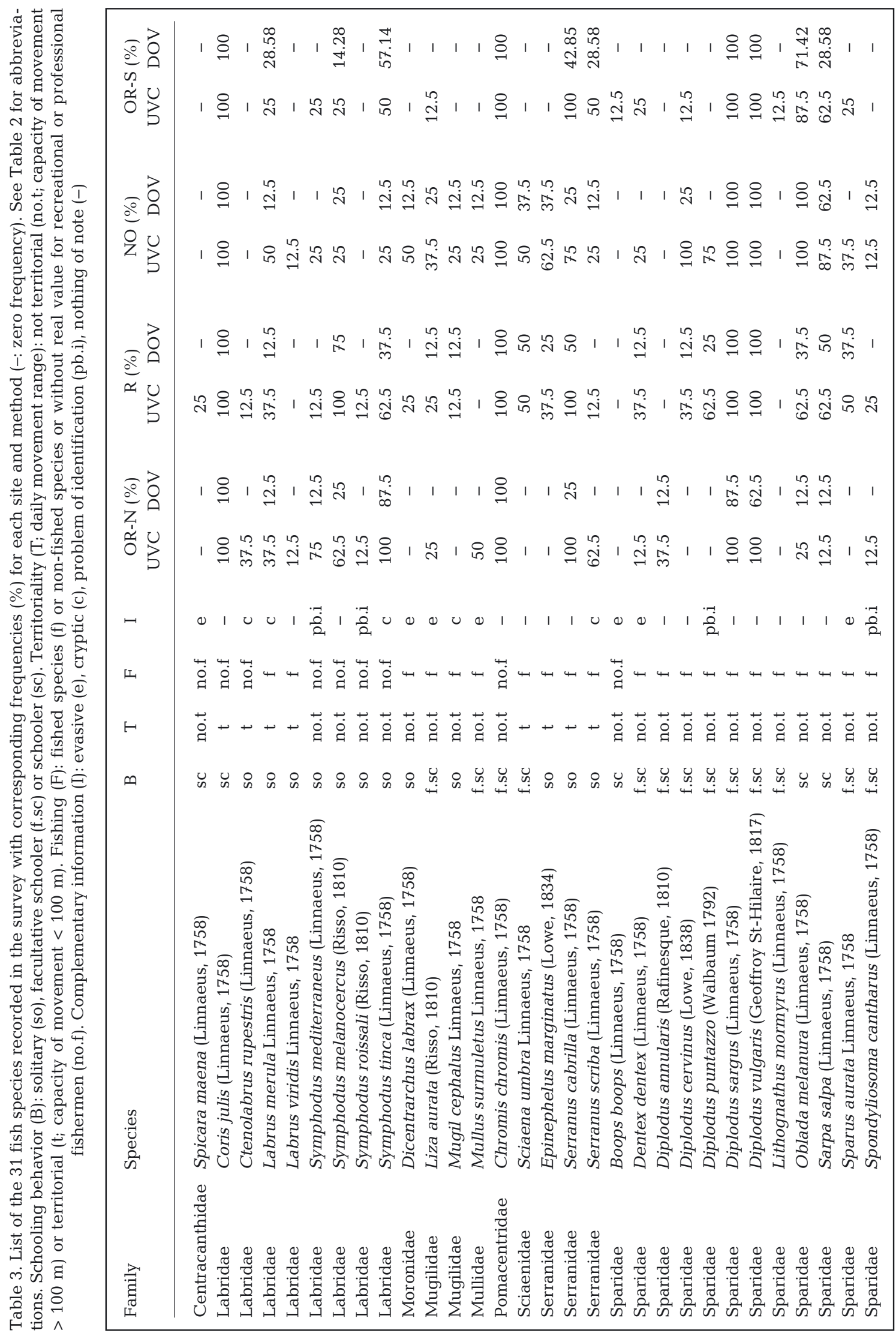


counted by UVC only (Boops boops, Ctenolabrus rupestris, Labrus viridis, Lithognathus mormyrus, Spicara maena and Symphodus roissali). Chromis chromis and Coris julis, gregarious and non-evasive species, presented the same frequencies in the different sites for both methods. Twelve species showed a similar trend in frequencies using both methods, but with slightly lower frequencies for DOV. These 12 species are for the most part territorial, non-gregarious and non-evasive. A total of 10 species out of 30 showed a different pattern between the methods. Of these 10 species, 6 were always detected by both methods at NO but were not detected by DOV when these species were recorded by UVC at sites outside NO. These 6 species are evasive or cryptic and did not form schools.

\section{Structure of fish assemblage analysis}

The nMDS plot suggests there is no marked difference between the detection structure of fish assemblage with UVC and DOV or depth (Fig. 5). However, the nMDS plot clearly separates the sites into 2 groups (NO, R and OR-S vs. OR-N), with a similarity of $40 \%$ within the assemblage observed in the grouped sampling sites (Fig. 5). The PERMANOVA test also indicates a difference in assemblage among sites $(p=0.0001)$ and an interaction between sites and methods $(p<0.05)$. A significant difference regarding the detection of the structure of fish assemblages between the UVC and DOV methods ( $p<$ $0.0005)$ and among depths $(p<0.05)$ was also observed. The post hoc test reveals that for UVC, all sites showed differences among themselves, except for NO and OR-S. The results are similar for DOV, except that the assemblage at R and OR-S can be considered as the same (Table 4 ).
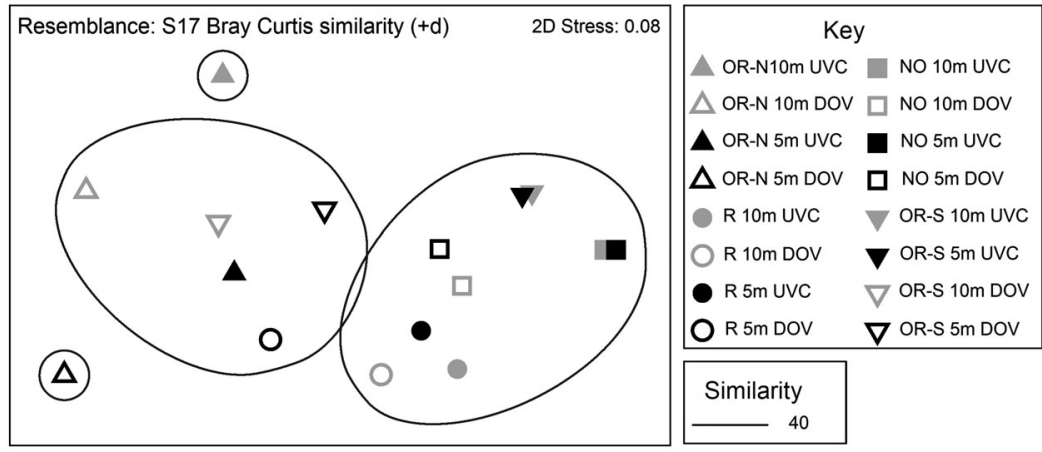

Fig. 5. Two-dimensional non-metric multi-dimensional scaling ordination of species abundance observed at each site, depth and method in and near the marine protected area. Cluster grouping with similarity level of $40 \%$. See Table 2 for abbreviations
Table 4. Student's t-test with 999 permutations comparing the difference in structures of fish assemblages by sampling method. See Table 2 for abbreviations

\begin{tabular}{|c|c|c|c|c|}
\hline Method & $\longrightarrow$ & te- & $t$ & $\mathrm{p}$ \\
\hline \multirow[t]{6}{*}{ UVC } & OR-N & $\mathrm{R}$ & 1.66 & 0.0185 \\
\hline & & $\mathrm{NO}$ & 3.26 & 0.0002 \\
\hline & & OR-S & 2.494 & 0.0002 \\
\hline & $\mathrm{R}$ & NO & 2.075 & 0.00047 \\
\hline & & OR-S & 1.896 & 0.00023 \\
\hline & NO & OR-S & 1.341 & 0.118 \\
\hline \multirow[t]{6}{*}{ DOV } & OR-N & $\mathrm{R}$ & 1.558 & 0.0322 \\
\hline & & $\mathrm{NO}$ & 2.504 & 0.0007 \\
\hline & & OR-S & 1.553 & 0.00097 \\
\hline & $\mathrm{R}$ & NO & 1.881 & 0.0185 \\
\hline & & OR-S & 1.241 & 0.148 \\
\hline & NO & OR-S & 1.885 & 0.00077 \\
\hline
\end{tabular}

\section{Cost-benefit analysis}

The cost-benefit analysis suggests that DOV is less cost-effective than UVC on an hourly or daily basis (Table 5). The time needed to generate data per station is similar for both methods $(4 \mathrm{~h})$. The time used for data extraction is greater for DOV (2 d) than for UVC $(0.25 \mathrm{~d})$.

\section{DOV contribution to study reserve effect}

Chi-squared tests carried out for each sampling site show that fish aggregation codes were not present in the same proportion at a given site (OR-N: $\chi^{2}=98.67$, $\mathrm{p}<0.05 ; \mathrm{R}: \chi^{2}=27.67, \mathrm{p}<0.05 ; \mathrm{NO}: \chi^{2}=23.33, \mathrm{p}<$ 0.05 ; and OR-S: $\chi^{2}=45, \mathrm{p}<0.05$ ). Concerning the set of sites, fish aggregation codes were not the same among sites $\left(\chi^{2}=99.30\right.$, $p<0.0001)$. Fig. 6 shows that the 'No fish', 'Isolated' and 'Scattered' classes dominated at all sites (>60\%). The 'No fish' code was more common at OR-N than at the other sites $(70 \%)$. All fish aggregation codes were present at each sampling site, except the 'Patch' code. The 'Patch' class was found only at sites located within the marine reserve ( $\mathrm{R}$ and NO). Moreover, the codes corresponding to high densities were more frequent with increasing protection status and varied inversely with the codes describing low density. 
Table 5. Cost-benefit per station for both sampling strategies: UVC (underwater visual census) and DOV (diver-operated video). The 2 parts of the study, field sampling and data analysis, were considered. The daily dive time for a diver takes into account the time of transport and of sampling at the study site

\begin{tabular}{|c|c|c|c|c|}
\hline & $\longrightarrow$ UVC & - & DOV & 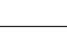 \\
\hline \multicolumn{5}{|l|}{ Work on an hourly basis } \\
\hline \multirow[t]{3}{*}{ Sampling per site } & (A) Number of transects & 8 & (a) Number of transects & 8 \\
\hline & (B) Transect sampled $\mathrm{h}^{-1}$ & 2 & (b) Transect sampled $\mathrm{h}^{-1}$ & 2 \\
\hline & (C) Work hours (A/B) & 4 & (c) Work hours $(\mathrm{a} / \mathrm{b})$ & 4 \\
\hline \multirow[t]{3}{*}{ Analysis per site } & (D) Data processing & 1 & (d) Visualization of tape & 1.5 \\
\hline & (E) Analysis, data acquisition & 0.5 & (e) Tape processing & 0.5 \\
\hline & (F) Work hours (D + E) & 1.5 & (f) Work hours $[(\mathrm{a} \times \mathrm{d})+\mathrm{e}]$ & 12.5 \\
\hline Total & $\mathrm{C}+\mathrm{F}$ & 5.5 & $\mathrm{C}+\mathrm{f}$ & 16.5 \\
\hline \multicolumn{5}{|l|}{ Work on a daily basis } \\
\hline Sampling per station & 1 diver $\mathrm{d}^{-1}$ and $1 \mathrm{~h}$ dive $^{-1}$ & 1 & 1 diver $\mathrm{d}^{-1}$ and $1 \mathrm{~h}$ dive $^{-1}$ & 1 \\
\hline Analysis per station & 1 worker and $6 \mathrm{~h} \mathrm{~d}^{-1}$ & 0.25 & 1 worker and $6 \mathrm{~h} \mathrm{~d}^{-1}$ & 2 \\
\hline Total & & 1.25 & & 3 \\
\hline
\end{tabular}

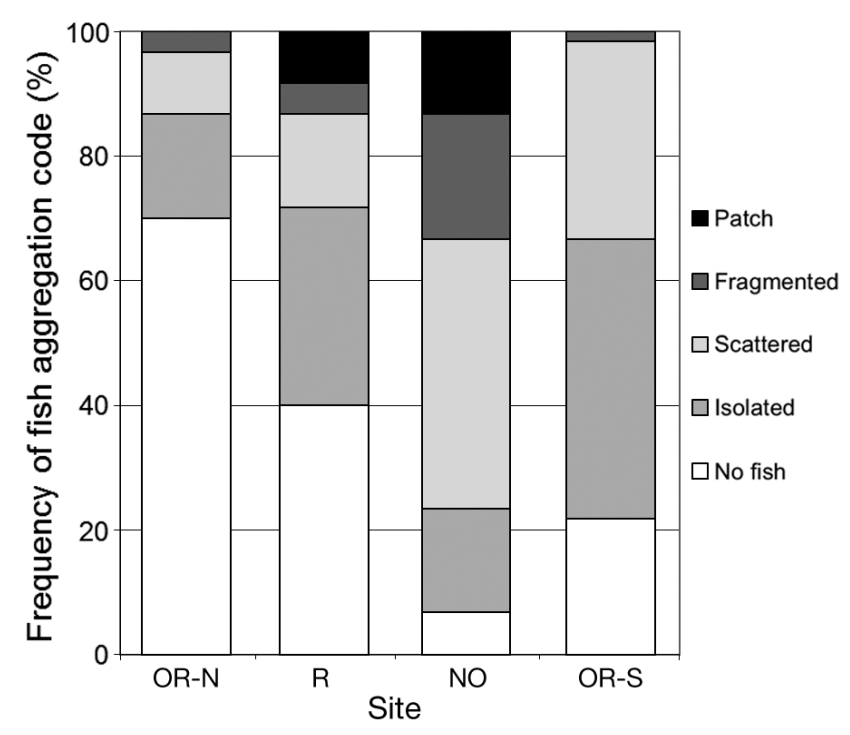

Fig. 6. Frequency of 'fish aggregation code' in percentage by site. See Table 2 for abbreviations

\section{DISCUSSION}

\section{Suitability of DOV for studying reserve effect}

The differences in abundance and species richness among sites detected by UVC in the present study are similar to those reported in previous studies for Cerbère-Banyuls MPA (Bell 1983, Dufour et al. 1995, Harmelin-Vivien et al. 2008). Abundance was lower at OR-N than at NO due to artisanal and recreational fishing pressures at OR-N, in contrast to NO where they are prohibited (Bell 1983, Dufour et al. 1995). The difference between OR-N and OR-S could be due to the fact that these activities are more important in the north of the marine reserve than in the south (Goñi et al. 2008). Furthermore, this difference could also be due to a spillover effect. The mean spillover distance is $<2 \mathrm{~km}$ around the no-take area for the Cerbère-Banyuls MPA (Harmelin-Vivien et al. 2008). OR-N, $4 \mathrm{~km}$ from NO, cannot benefit from spillover, in contrast to OR-S, located at $2 \mathrm{~km}$. The greater species richness inside the Cerbère-Banyuls MPA (NO and R) than at OR-N is due to the presence of certain species like (Epinephelus marginatus, Sciaena umbra and Diplodus cervinus) that were encountered exclusively inside the marine reserve. This exclusivity is due to their high sensitivity to artisanal or recreational fishing pressure and their low production/biomass ratio (Francour et al. 2001, Lenfant et al. 2003).

In the present study, abundance and species richness were always less when measured using DOV than with UVC. This difference is a phenomenon widely encountered in other studies (Tessier et al. 2005, Stobart et al. 2007, Colton \& Swearer 2010, Pelletier et al. 2011) and could be due to the fact that the sampling area differs slightly between the 2 methods. The angle of the camera field of view can generate this difference. The angle of view of a diver is ca. $80^{\circ}$ (Lam et al. 2006), and a diver is able to turn his or her head to census fish outside his or her field of view. This is not possible with the fixed angle of view of DOV. In addition, the behaviour of shy and evasive species is clearly influenced by the noise generated by the diver operating a DOV census (Francour et al. 1999, Cole et al. 2007). Consequently, these shy spe- 
cies were probably not sampled along the DOV transect, yielding lower abundance and lower species richness. Only fixed video recorders, without divers around, are able to record shy species (Francour et al. 1999). In contrast, a diver performing UVC can detect these shy species at the limit of the transect belt (Harmelin-Vivien et al. 1985). Therefore, DOV is not asuitable substitute for UVC in cases where an observer wants to characterize fish assemblages, even if its bias (underestimation of cryptic, mobile and nocturnal fishes) is well known (Harmelin-Vivien et al. 1985, Harmelin-Vivien \& Francour 1992).

Concerning abundance, DOV did not detect the difference between OR-N and OR-S, probably due to the lower values calculated in comparison to UVC (smaller sampling area; see above). A minimum transect surface is recommended to study ichthyofauna (Harmelin-Vivien et al. 1985), and a smaller one can prevent the detection of difference among sites. Consequently, no significant difference was detected between OR-N and OR-S, but a difference was detected between OR-N and NO.

DOV, like UVC, indicated lower species richness outside the MPA, but for different sites: OR-N and OR-S, respectively, for DOV and UVC. This difference is probably linked to the low resolution (number of pixels) of the video or computer monitor, which limited the accurate identification of fish at species level. For example, tiny details allow the underwater identification of some species, such as Symphodus spp. Their identification on a computer is more complicated because its resolution is less than that of the human eye. Some anatomic details or characteristic colours, already difficult to discern in UVC, are even less recognizable in DOV. Poor video identification of species of the genus Symphodus could probably explain the difference between the 2 methods or among sites.

However, despite these biases, DOV can detect a reserve effect like UVC did, but DOV is less powerful. DOV may be appropriate to sample a part of the fish assemblage: the non-shy, non-cryptic and easily identifiable species, such as most of the target species. The cost-benefit analysis showed a much longer data collection time per transect via DOV than with UVC. This time can be reduced by the analysis of a few selected species. Some studies using underwater video, essentially employing stationary cameras, came to the same conclusion (Francour et al. 1999, Stobart et al. 2007, Pelletier et al. 2011).

As mentioned before, using the UVC method on multiple sites induces temporal bias in the case of a unique diving observer. Multiple observers, diving simultaneously, remove this effect but introduce an observer bias. The use of the DOV method can reduce temporal and observer variability.

DOV would allow the study of more parameters than UVC. In the field, an observer cannot simultaneously record the size, number, species, fish aggregation along transect, type of substrate or cover and their percentage, for example. With too much information to write at the same time, the risk of information loss (by forgetting to note or by missing a fish that crosses the transect) increases, even if there is more than one observer. However, this expanded data collection is possible with video. DOV also allows data archiving. This would enable the use of the video for another study or the comparison of the evolution of substrates over time.

However, DOV is not suitable for measuring fish sizes. This is only possible using stereo-video (Harvey et al. 2002, Dunbrack 2006, Watson et al. 2010), which requires more sophisticated material, making it more costly and less easy to implement in the field. Thus, DOV cannot be used by all organisations conducting fish monitoring, unlike UVC. This is especially true for simultaneous multi-site studies.

\section{Contribution of DOV in studying reserve effect}

Of the few studies that have used DOV (also stereo-video) to study ichthyofauna (Tessier et al. 2005, Langlois et al. 2010, Watson et al. 2010), none have focused on finding an additional metric in this regard. Yet, DOV provides access to the spatial component of a transect through the use of aggregation metrics. Therefore, it appeared interesting to see if access to this component could provide a complement to UVC for fish fauna studies.

The analysis of fish aggregation showed an unequal inter- and intra-site distribution of fish aggregation codes. 'No fish' was the fish aggregation code that dominated at OR-N. This could be explained by the generally low fish abundance found in this site outside the MPA. In contrast, the 'Patch' codetranslating the greatest abundance - was found only at sites located inside the MPA. It appeared also that the higher the protection status of a site, the higher the frequency of the codes describing important groupings of fish. The 2 types of fish schools observed (patchy and fragmented) were principally composed of species targeted by fishing, such as Diplodus vulgaris, D. sargus and Sciaena umbra. The variation of the frequency of the codes could be the result of protection status but could also be the result 
of a variation of habitat among sites. Some studies have shown the impact of habitat complexity on fish density (Claudet et al. 2011). It is possible that this is the same for the species cited previously. However, this hypothesis can be rejected because our observation during the sampling and a fine mapping of the study area show a very similar habitat complexity among all of the sampling sites. Furthermore, this parameter is a less-determinant factor for the difference of abundance or species richness among sites than the protection status in shallow water $(\leq 10 \mathrm{~m})$ (Claudet et al. 2011). As habitat complexity probably does not play a role here, the variation of the frequency of the codes detected in the present study could be the result of the protection status. Due to the high abundance in the sites inside the MPA, the lack of space could drive an aggregation of fish (Ward \& Hart 2005), which can also be linked to a mechanism of density dependence. Indeed, an increase in the number of individuals increases the encounters with other members of the species and thus promotes the formation of a school. Furthermore, an increase in the number of schools could increase their probability of meeting and their amalgamation. This phenomenon has been observed for terrestrial species (Pépin \& Gerard 2008). In the present study, the ecological roles of aggregation have not been considered, such as reproduction, nutrition and strategies to escape predators. The last hypothesis should be explored because the main result of a reserve effect is to increase the presence of large predators (Francour et al. 2010). DOV data, at a species level, have to be linked to aggregation phenomena to understand ecological patterns. Nevertheless, in the context of our work, fish aggregation is a variable that can be used to study the reserve effect with DOV technique.

\section{CONCLUSION}

The present study shows that DOV can detect a reserve effect when the impact is significant. It is difficult for DOV to detect this effect when it is weak, but it may be of use when studying a targeted species or an easily identifiable species, in this case Epinephelus marginatus, Diplodus cervinus, D. vulgaris, D. sargus or Sciaena umbra. The present work also shows that the analysis of fish aggregation along transects can help to detect a reserve effect for some species. This is an interesting metric that has not been used to date. This raises the question of how protection status may affect the behaviour of schooling for some species. DOV appears to be a promising method that can be very useful for MPA managers, notably to monitor target fishes. However, a multisite study to verify whether this method is valid for sites other than the Cerbère-Banyuls marine reserve is necessary.

Acknowledgements. This research was financially supported by the Natural Marine Reserve of Cerbère-Banyuls, General Council of Pyrénées-Orientales, the program LITEAU-PAMPA and the program ANR GAIUS. We thank the Natural Marine Reserve of Cerbère-Banyuls also for their technical support. Furthemore, we thank L. Mangialajo for help during the data analysis. Thanks also to G. Fowler for his English corrections.

\section{LITERATURE CITED}

Alcala AC, Russ GR (1990) A direct test of the effects of protective management on abundance and yield of tropical marine resources. ICES J Mar Sci 47:40-47

Anderson MJ (2000) NPMANOVA: a FORTRAN computer program for non-parametric multivariate analysis of variance (for any two-factor ANOVA design) using permutation tests. Department of Statistics, University of Auckland

$>$ Bell JD (1983) Effects of depth and marine reserve fishing restrictions on the structure of a rocky reef fish assemblage in the north-western Mediterranean Sea. J Appl Ecol 20:357-369

Bianchi CN, Morri C (2000) Marine biodiversity of the Mediterranean Sea: situation, problems and prospects for future research. Mar Pollut Bull 40:367-376

Boland GS, Lewbel GS (1986) Estimation of demersal fish densities in biological surveys using underwater television systems. Oceans 2:9-13

Cappo M, Speare P, De'ath G (2004) Comparison of baited remote underwater video stations (BRUVS) and prawn (shrimp) trawls for assessments of fish biodiversity in inter-reefal areas of the Great Barrier Reef Marine Park. J Exp Mar Biol Ecol 302:123-152

Clarke KR, Gorley RN (2006) PRIMER v6: user manual/tutorial. PRIMER-E, Plymouth

> Claudet J, García-Charton JA, Lenfant P (2011) Combined effects of levels of protection and environmental variables at different spatial resolutions on fish assemblages in a marine protected area. Conserv Biol 25:105-114

Cole RG, Syms C, Davey NK, Gust N and others (2007) Does breathing apparatus affect fish counts and observations? A comparison at three New Zealand fished and protected areas. Mar Biol 150:1379-1395

Colton MA, Swearer SE (2010) A comparison of two survey methods: differences between underwater visual census and baited remote underwater video. Mar Ecol Prog Ser 400:19-36

Côté IM, Mosqueira I, Reynolds JD (2001) Effects of marine reserve characteristics on the protection of fish populations: a meta-analysis. J Fish Biol 59:178-189

> Denny CM, Willis TJ, Babcock RC (2004) Rapid recolonisation of snapper Pagrus auratus: Sparidae within an offshore island marine reserve after implementation of notake status. Mar Ecol Prog Ser 272:183-190

Di Franco A, Coppini G, Pujolar JM, De Leo GA and others (2012) Assessing dispersal patterns of fish propagules 
from an effective Mediterranean marine protected area. PLoS ONE 7:e52108

Dufour V, Jouvenel JY, Galzin R (1995) Study of a Mediterranean reef fish assemblage. Comparisons of population distributions between depths in protected and unprotected areas over one decade. Aquat Living Resour 8:17-25

Dunbrack RL (2006) In situ measurement of fish body length using perspective-based remote stereo-video. Fish Res 82:327-331

Fenberg PB, Caselle JE, Claudet J, Clemence M and others (2012) The science of European marine reserves: status, efficacy, and future needs. Mar Policy 36:1012-1021

$>$ Ferraris J, Pelletier D, Kulbicki M, Chauvet C (2005) Assessing the impact of removing reserve status on the Abore Reef fish assemblage in New Caledonia. Mar Ecol Prog Ser 292:271-286

Forcada A, Bayle-Sempere JT, Valle C, Sánchez-Jerez P (2008) Habitat continuity effects on gradients of fish biomass across marine protected area boundaries. Mar Environ Res 66:536-547

Francour P (1994) Pluriannual analysis of the reserve effect on ichtyofauna in the Scandola natural reserve (Corsica, northern-occidental Mediterranean). Oceanol Acta 17: 309-317

Francour P (1997) Fish assemblages of Posidonia oceanica beds at Port-Cros (France, NW Mediterranean): assessment of composition and long-term fluctuations by visual census. PSZNI Mar Ecol 18:157-173

Francour P, Liret C, Harvey E (1999) Comparison of fish abundance estimates made by remote underwater and visual census. Nat Sicil 23(Suppl):155-168

Francour P, Harmelin JG, Pollard D, Sartoretto S (2001) A review of marine protected areas in the northwestern Mediterranean region: sitting, usage, zonation and management. Aquat Conserv 11:155-188

Francour P, Mangialajo L, Pastor J (2010) Mediterranean marine protected areas and non-indigenous fish spreading. In: Golani D, Appelbaum-Golani B (eds) Fish invasions of the Mediterranean Sea: change and renewal. Pensoft, Sofia, p $127-144$

> García-Charton JA, Pérez-Ruzafa Á, Sánchez-Jerez P, BayleSempere JT, Reñones O, Moreno D (2004) Multi-scale spatial heterogeneity, habitat structure, and the effect of marine reserves on Western Mediterranean rocky reef fish assemblages. Mar Biol 144:161-182

> Gell FR, Roberts CM (2003) Benefits beyond boundaries: the fishery effects of marine reserves. Trends Ecol Evol 18: 448-455

Goñi R, Alderstein S, Alvarez-Berastegui D, Forcada A and others (2008) Spillover from six western Mediterranean marine protected areas: evidence from artisanal fisheries. Mar Ecol Prog Ser 366:159-174

> Guidetti P (2007) Potential of marine reserves to cause community-wide changes beyond their boundaries. Conserv Biol 21:540-545

- Guidetti P, Sala E (2007) Community-wide effects of marine reserves in the Mediterranean Sea. Mar Ecol Prog Ser 335:43-56

> Harmelin JG, Bachet F, Garcia F (1995) Mediterranean marine reserves: fish indices as tests of protection efficiency. PSZNI Mar Ecol 16:233-250

Harmelin-Vivien M, Francour P (1992) Trawling or visual censuses? Methodological bias in the assessment of fish populations in seagrass beds. PSZNI Mar Ecol 13: 41-51
Harmelin-Vivien ML, Harmelin JG, Chauvet C, Duval C and others (1985) The underwater observation of fish communities and fish populations: methods and problems. Rev Ecol Terre Vie 40:466-539

> Harmelin-Vivien M, Le Direach L, Bayle-Sempere J, Charbonnel E and others (2008) Gradients of abundance and biomass across reserve boundaries in six Mediterranean marine protected areas: evidence of fish spillover? Biol Conserv 141:1829-1839

$>$ Harvey E, Fletcher D, Shortis M (2002) Estimation of reef fish length by divers and by stereo-video: a comparison of the accuracy and precision in the field on living under operational conditions. Fish Res 57:255-265

Harvey E, Fletcher D, Shortis MR, Kendrick GA (2004) A comparison of underwater visual distance estimates made by scuba divers and a stereo-video system: implications for underwater visual census of reef fish abundance. Mar Freshw Res 55:573-580

Harvey E, Cappo M, Butler JJ, Hall N, Kendrick GA (2007) Bait attraction affects the performance of remote underwater video stations in assessment of demersal fish community structure. Mar Ecol Prog Ser 350:245-254

> Harvey E, Bulter J, McLean D, Shand J (2012) Contrasting habitat use of diurnal and nocturnal fish assemblages in temperate Western Australia. J Exp Mar Biol Ecol 426-427:78-86

Hilty J, Merenlende A (2000) Faunal indicator taxa selection for monitoring ecosystem health. Biol Conserv 92: 185-197

Himes AH (2007) Performance indicators in MPA management: using questionnaires to analyze stakeholder preferences. Ocean Coast Manage 50:329-351

> Hussein C, Verdoit-Jarraya M, Pastor J, Ibrahim A and others (2011) Assessing the impact of artisanal and recreational fishing and protection on a white seabream (Diplodus sargus sargus) population in the north-western Mediterranean Sea, using a simulation model. Part 2: sensitivity analysis and management measures. Fish Res 108:174-183

> Lam K, Shin PKS, Bradbeer R, Randall D, Ku KKK, Hodgson P, Cheung SG (2006) A comparison of video and point intercept transect methods for monitoring subtropical coral communities. J Exp Mar Biol Ecol 333:115-128

Landeau L, Terborgh J (1986) Oddity and the 'confusion effect' in predation. Anim Behav 34:1372-1380

Langlois TJ, Harvey E, Fitzpatrick B, Meeuwig JJ, Shedrawi G, Watson DL (2010) Cost-efficient sampling of fish assemblages: comparison of baited video stations and diver video transects. Aquat Biol 9:155-168

Lenfant P, Louisy P, Licari ML (2003) Recensement des mérous bruns (Epiphelus marginatus) de la réserve de Cerbère-Banyuls (France, Méditerranée) effectué en septembre 2001, après 17 années de protection. Cybium $27: 27-36$

Letourneur Y, Ruitton S, Sartoretto S (2003) Environmental and benthic habitat factors structuring the spatial distribution of a summer infralittoral fish assemblage in the north-western Mediterranean Sea. J Mar Biol Assoc UK 83:193-204

Michalopoulos C, Auster PJ, Malatesta RJ (1992) A comparison of transect and species-time counts for assessing faunal abundance from video surveys. Mar Technol Soc J $26: 27-31$

Mosquera I, Côté IM, Jennings S, Reynolds JD (2000) Conservation benefits of marine reserves for fishes populations. 
Anim Conserv 3:321-332

Pauly D, Christensen V, Dalsgaard J, Froese R, Torres FJ (1998) Fishing down marine food webs. Science 279: 860-863

Pelletier D, Leleu K, Mou-Tham G, Guillemot PN, Chabanet P (2011) Comparison of visual census and high definition video transects for monitoring coral reef fish assemblages. Fish Res 107:84-93

Pépin G, Gerard JF (2008) Group dynamics and local population density dependence of group size in the Pyrenean chamois, Rupicpra pyrenaica. Anim Behav 75:361-369

R Development Core Team (2008) R: a language and environment for statistical computing. R Foundation for Statistical Computing, Vienna

Sabatés A, Zabala M, García-Rubies A (2003) Larval fish communities in the Medes Islands Marine Reserve (Northwest Mediterranean). J Plankton Res 25:1035-1046

Sahyoun R, Bussotti S, Di Franco A, Navone A, Panzalis P, Guidetti P (2013) Protection effects on Mediterranean fish assemblages associated with different rocky habitats. J Mar Biol Assoc UK 93:425-435

Seytre C, Francour P (2009) The Cap Roux MPA (SaintRaphaël, French Mediterranean): changes in fish assemblages within four years of protection. ICES J Mar Sci 66: 180-187

Sokal RR, Rohlf FJ (1995) Biometry: the principles and practice of statistics in biological research. WH Freeman,

Editorial responsibility: Riccardo Cattaneo-Vietti, Genova, Italy
New York, NY

Stobart B, García-Charton JA, Espejo C, Rochel E and others (2007) A baited underwater video technique to assess shallow-water Mediterranean fish assemblages: methodological evaluation. J Exp Mar Biol Ecol 345:158-174

Tessier E, Chabanet P, Pothin K, Soria M, Lasserre G (2005) Visual censuses of tropical fish aggregations on artificial reefs: slate versus video recording techniques. J Exp Mar Biol Ecol 315:17-30

Vacchi M, Bussotti P, Guidetti P, La Mesa G (1998) Study of the coastal fish assemblage in the marine reserve of the Ustica Island (southern Tyrrhenian Sea). Ital J Zool 65(Suppl):281-286

- Ward AJW, Hart PJB (2005) Foraging benefits of schooling with familiars may be exploited by outsiders. Anim Behav 69:329-335

> Watson DL, Harvey E, Fitzpatrick BM, Langlois TL, Shedrawi G (2010) Assessing reef fish assemblage structure: How do different stereo-video techniques compare? Mar Biol 157:1237-1250

Willis TJ, Babcock RC (2000) A baited underwater video system for the determination of relative density of carnivorous reef fish. Mar Freshw Res 51:755-763

Willis TJ, Millar RB, Badcock RC (2000) Detection of spatial variability in relative density of fishes: comparison of visual census, angling, and baited underwater video. Mar Ecol Prog Ser 198:249-260

Submitted: December 3, 2012; Accepted: February 28, 2013 Proofs received from author(s): May 2, 2013 